\title{
FFR nie zawsze rozstrzygający... Chora z nieistotną hemodynamicznie zmianą w naczyniu wieńcowym i z zawałem serca
}

\section{FFR not always conclusive... A patient with a hemodynamically insignificant lesion in coronary artery and myocardial infarction}

\author{
Paweł Czerwonka ${ }^{1}$, Iwona Gorczyca-Michta ${ }^{1}$, Alicja Stępień-Wałek ${ }^{1}$, Beata Wożakowska-Kapłon ${ }^{1,2}$ \\ ${ }^{1}$ I Klinika Kardiologii i Elektroterapii Świętokrzyskiego Centrum Kardiologii w Kielcach \\ ${ }^{2}$ Wydział Lekarski i Nauk o Zdrowiu Uniwersytetu Jana Kochanowskiego w Kielcach
}

\section{Streszczenie}

Ocena cząstkowej rezerwy przepływu (FFR) ma duże znaczenie w identyfikacji istotnych hemodynamicznie zwężeń w obrębie tętnic wieńcowych. Jej wynik jest ważnym kryterium w aspekcie dalszego postępowania terapeutycznego. Zwraca się jednak uwagę, że nie powinno ono zależeć jedynie od dodatniego wyniku FFR, zwłaszcza w naczyniach o subkrytycznym charakterze zmian.

Słowa kluczowe: FFR, fractional flow reserve, zmiany subkrytyczne, NSTEMI

Folia Cardiologica 2017; 12, 2: 211-214

\section{Wstęp}

Badania obrazowe pozwalają rozpoznać nieprawidłowości i ułatwiają wybór postępowania. Badaniem o rosnącym znaczeniu jest ocena cząstkowej rezerwy przepływu (FFR, fractional flow reserve), będąca ilorazem maksymalnego przepływu krwi przez naczynie i hipotetycznego przepływu przez to naczynie w sytuacji braku zwężenia. Podkreśla się niewystarczającą wartość predykcyjną koronarografii w identyfikacji zmian powodujących niedokrwienie mięśnia sercowego oraz niską czułość i specyficzność testu wysiłkowego, szczególnie u pacjentów z wielonaczyniową chorobą wieńcową oraz u kobiet. Dlatego FFR, w połączeniu z wizualną oceną angiograficzną, stało się metodą referencyjną w rozpoznawaniu zwężeń wywołujących istotne niedokrwienie miokardium. W ocenie klinicznej nasilenia dławicy należy jednak uwzględnić również inne czynniki, takie jak indywidualne predyspozycje poszczególnych cho- rych i ich tolerancję na niedokrwienie mięśnia sercowego. Ponadto podkreśla się, że dolegliwości dławicowe moga wynikać z innych mechanizmów. niezwiązanych ze zmianami miażdżycowymi, takich jak dysfunkcja mikrokrążenia czy ogniskowy lub uogólniony skurcz tętnicy.

\section{Opis przypadku}

Pacjentka w wieku 71 lat, z nadciśnieniem tętniczym 3. stopnia, hipercholesterolemią i obciążona wywiadem rodzinnym, została przyjęta do kliniki kardiologii z powodu niestabilnej dławicy piersiowej (UA, unstable angina). Przy przyjęciu pacjentka była w dobrym stanie ogólnym; ciśnienie tętnicze wynosiło 130/70 mm Hg, a czynność serca 80/min. W badaniach laboratoryjnych przy przyjęciu stwierdzono następujące wartości oznaczonych parametrów: stężenie troponiny T (TnT, troponin T) 9,2 ng/l (norma < 14 ng/l), aktywność kinazy fosfokreatynowej (CPK, creatine

Adres do korespondencji: lek. Paweł Czerwonka, I Klinika Kardiologii i Elektroterapii, Świętokrzyskie Centrum Kardiologii, ul. Grunwaldzka 45, 25-736 Kielce, e-mail: czerwonka.pawel@gmail.com 


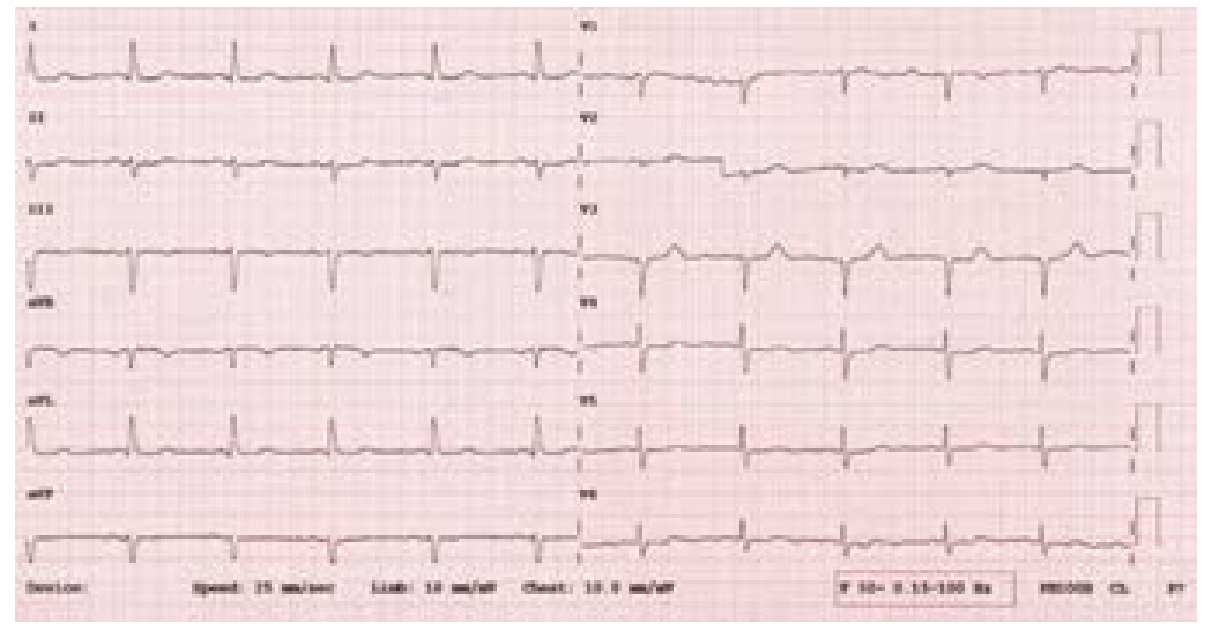

Rycina 1. Dwunastoodprowadzeniowe badanie elektrokardiograficzne wykonane przy przyjęciu (25 mm/s): rytm zatokowy o częstości 66/min, zespoły QS w odprowadzeniach V1-V3, ujemne załamki T w odprowadzeniu III, płaskie załamki T w odprowadzeniu aVF

phosphokinase) 97 j./I (norma 45-300 j./I), stężenie frakcji sercowej kinazy kreatynowej (CK-MB) $18 \mathrm{j} . / /$ (norma 0-39 j./I). W wykonanym 12-odprowadzeniowym badaniu elektrokardiograficznym (EKG) stwierdzono rytm zatokowy o częstości 66/min, zespoły QS w odprowadzeniach V1-V3, ujemne załamki T w odprowadzeniu III i płaskie załamki T w odprowadzeniu aVF (ryc. 1).

W badaniu echokardiograficznym nie stwierdzono odcinkowych zaburzeń kurczliwości mięśnia sercowego; frakcja wyrzutowa lewej komory wynosiła 60\%. W koronarografii stwierdzono zwężenie w segmencie środkowym gałęzi międzykomorowej przedniej lewej tętnicy wieńcowej (LAD, left anterior descending) do 50-70\%, zwężenie gałęzi przekątnej (inaczej ‘diagonalnej' [Dg, diagonal]) w odcinku początkowym do 50-70\% oraz zwężenie gałęzi marginalnej (Mg, marginal) maksymalnie do 70\%. W obrębie prawej tętnicy wieńcowej (RCA, right coronary artery) - dominującej, oddającej gałąź lewokomorową i międzykomorową tylną, nie zobrazowano istotnych zmian (ryc. 2).

U pacjentki wykonano FFR LAD oraz gałęzi Dg. Uzyskano następujące wyniki: FFR LAD 0,94, FFR Dg 0,87 (ryc. 3). Ze względu na uzyskane wartości FFR, świadczące o zachowanej rezerwie przepływu wieńcowego, pacjentkę zakwalifikowano do dalszego leczenia zachowawczego. W 1. dobie po wykonaniu koronarografii chora zgłosiła ból zamostkowy o typowej charakterystyce i umiejscowieniu. W kontrolnych badaniach stwierdzono wzrost stężenia TnT do 57,8 ng/l oraz aktywności CK-MB do 78 j./l. W wykonanym wówczas badaniu EKG wykazano cechy ostrego niedokrwienia obniżenie odcinka ST w odprowadzeniach V3-V4 oraz V5 z ujemnymi załamkami T w wymienionych odprowadzeniach (ryc. 4). Rozpoznano zawał serca bez uniesienia odcinka ST (NSTEMI, non-ST-elevation myocardial infarction). Chorą zakwalifikowano do angioplastyki zwężonych naczyń. Wykonano angioplastykę LAD i Dg z implantacją dwóch

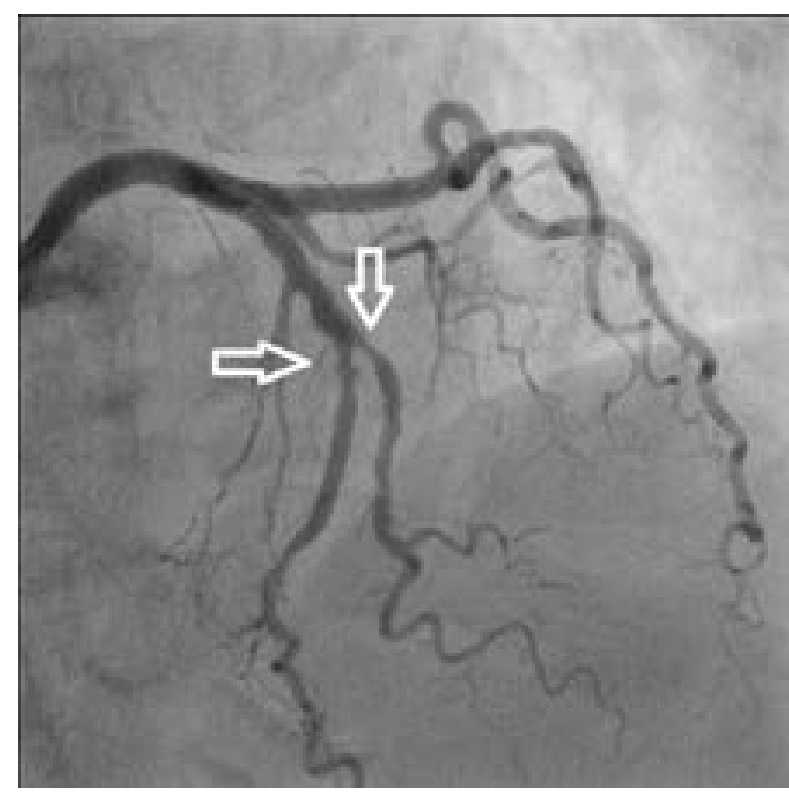

Rycina 2. Obraz angiograficzny naczyń wieńcowych - zwężenia w obrębie przedniej lewej tętnicy wieńcowej (LAD, left anterior descending) i gałęzi diagonalnej (Dg, diagonal) (zaznaczono strzałkami)

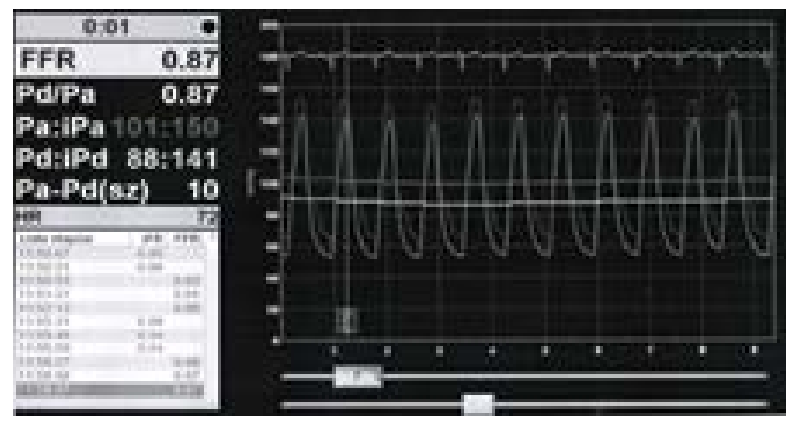

Rycina 3. Ocena cząstkowej rezerwy przepływu w gałęzi diagonalnej 


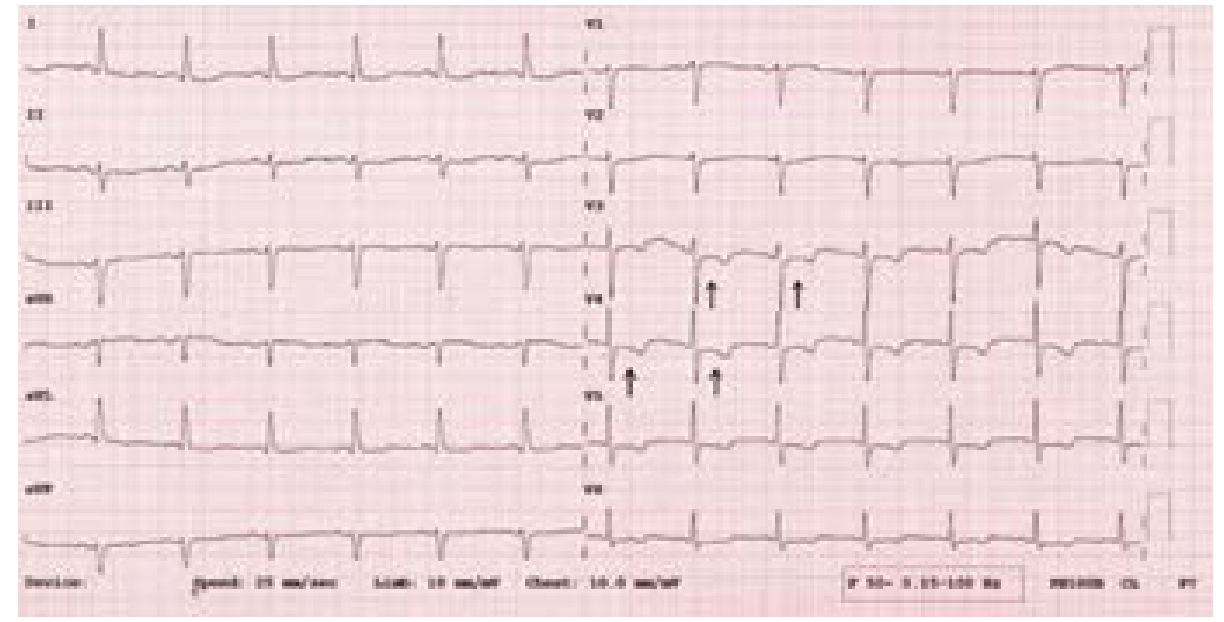

Rycina 4. Zapis elektrokardiograficzny wykonany w trakcie bólu

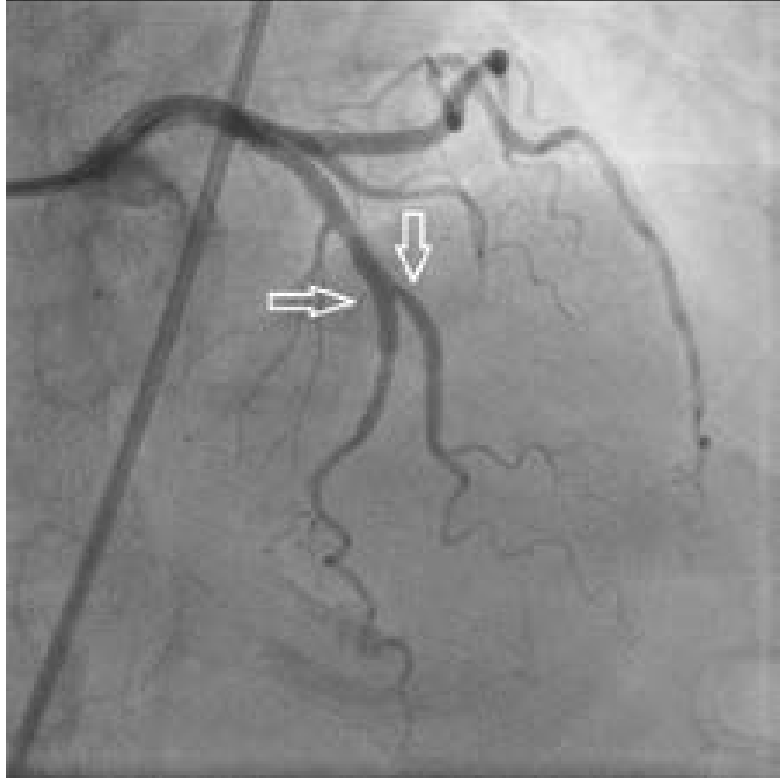

Rycina 5. Obraz koronarograficzny po wykonanej plastyce zwężonych tętnic (strzałkami wskazano miejsca implantowanych stentów)

stentów uwalniających lek (DES, drug eluting stent), uzyskując przepływ w naczyniach wynoszący TIMI 3 (Thrombolysis In Myocardial Infarction) (ryc. 5). W wyniku zastosowanego leczenia uzyskano ustąpienie dolegliwości i poprawę stanu ogólnego. Pacjentkę wypisano z kliniki w dobrym stanie ogólnym w 14. dobie hospitalizacji. W trakcie półrocznej obserwacji chora czuje się dobrze; nie zgłasza dolegliwości bólowych w klatce piersiowej.

\section{Dyskusja}

W obecnym postrzeganiu choroby wieńcowej zwraca się uwagę na złożony patomechanizm niedokrwienia mięśnia sercowego. U podłoża dolegliwości dławicowych, oprócz najczęściej stwierdzanego tła miażdżycowego, mogą leżeć inne mechanizmy, które istotnie ograniczają przepływ krwi w naczyniach wieńcowych. Są to między innymi dysfunkcja mikrokrążenia, ogniskowy lub uogólniony skurcz tętnicy, stan zapalny czy mechanizm restenozy [1, 2]. Pozamiażdżycowe czynniki wpływające na ograniczenie przepływu w naczyniach wieńcowych należy rozważać szczególnie u chorych z objawami, u których wyniki badań dodatkowych nie potwierdzają istotności zwężenia naczyń wieńcowych.

Czynnościowa ocena zwężeń tętnic wieńcowych, od FFR do badań perfuzji mięśnia sercowego, takich jak tomografia emisyjna pojedynczego fotonu (SPECT, single-photon emission computed tomography), pozwala na szczegółową ocenę angiograficznie granicznych zmian miażdżycowych w tętnicach wieńcowych i wybór odpowiedniej strategii terapeutycznej [3]. Początkowo uznawano, że wartość progowa oceny przepływu równa 0,75 pozwala wiarygodnie identyfikować zmiany wywołujące niedokrwienie, ale później powszechną akceptację uzyskało kryterium wynoszące 0,80, którego rolę w praktyce klinicznej zweryfikowano w badaniach z oceną klinicznych wyników leczenia [4]. W badaniu FAME (Fractional Flow Reserve Versus Angiography in Multivessel Evaluation) udowodniono wysoką skuteczność oceny FFR w diagnostyce hemodynamicznie istotnego zwężenia u pacjentów z wielonaczyniową chorobą wieńcową i jej wpływ na rokowanie u pacjentów, u których podjęto leczenie na podstawie wyniku FFR [5]. W nielicznych doniesieniach wykazano, że podejmowanie decyzji terapeutycznych na podstawie wyniku FFR u chorych z UA lub NSTEMI jest tak samo korzystne, jak u chorych ze stabilną dławicą piersiową [6].

U prezentowanej chorej oceny FFR dokonano w naczyniach ze zmianami subkrytycznymi. Wynik FFR wskazywał na brak istotności hemodynamicznej zmian w naczyniach. Osiągnięcie maksymalnego przepływu może być niemożliwe 
do oszacowania u chorych z UA lub NSTEMI ze względu na dynamiczny charakter zmian w tętnicach wieńcowych i obecność ostrej dysfunkcji mikrokrążenia. W rezultacie ocena FFR może być przeszacowana, a hemodynamiczna istotność zwężenia w tętnicy wieńcowej - niedoszacowana [7]. Według wytycznych dotyczących postępowania u chorych z ostrymi zespołami wieńcowymi bez uniesienia odcinka ST przydatność wyniku FFR w podejmowaniu decyzji dotyczących rewaskularyzacji wymaga przeprowadzenia dalszych badań [7]. Ocenione w badaniu angiograficznym zwężenie, powodujące krytyczne zmniejszenie FFR, może być różne. Zależy ono od konfiguracji i długości blaszki miażdżycowej, obszaru oraz żywotności mięśnia sercowego zaopatrywanego przez dane naczynie, sprawności krążenia obocznego, a także występowania dysfunkcji naczyń mikrokrążenia. Typową wartością progową dla istotnego zwężenia jest zwężenie średnicy naczynia o ponad 50\%, chociaż tylko $1 / 3$ wszystkich zwężeń średnicy naczynia o 50-70\% powoduje zmniejszenie FFR poniżej 0,80 [8].
Wprawdzie u opisywanej chorej wynik FFR nie wskazywał na istotność hemodynamiczną zwężeń w LAD i Dg, ale zwężenia te okazały się na tyle istotne, że powodowały typowe dolegliwości wieńcowe. Ponadto w etiologii NSTEMI u tej chorej należy rozważać współudział subkrytycznych zmian miażdżycowych oraz czynników nie miażdżycowych, takich jak dysfunkcja mikrokrążenia czy ogniskowy lub uogólniony skurcz tętnicy, których nie udokumentowano, ale mogły odgrywać istotną rolę niedokrwienną.

\section{Podsumowanie}

Wybór strategii leczenia w przypadku subkrytycznych zmian w naczyniach wieńcowych nie powinien się opierać wyłącznie na wynikach badań poświadczających istotność hemodynamiczną danych zmian. W każdym przypadku należy indywidualizować terapię, biorąc pod uwagę stan kliniczny chorego i w podejmowaniu decyzji terapeutycznych rozpatrywać te aspekty wspólnie.

\section{Abstract}

Assessment of partial flow reserve (FFR) is important in identifying hemodynamically significant coronary artery stenosis. Its result is an important criterion for further treatment. However, it should be noted that therapeutic decisions should not be made based only on the positive result of the FFR, especially in the blood vessels with subcritical lesions. Key words: FFR, fractional flow reserve, subcritical lesions, NSTEMI

Folia Cardiologica 2017; 12, 2: 211-214

\section{Piśmiennictwo}

1. Lanza GA, Careri G, Crea F. Mechanisms of coronary artery spasm. Circulation. 2011; 124(16): 1774-1782, doi: 10.1161/CIRCULATIONAHA.111.037283, indexed in Pubmed: 22007100.

2. Lanza GA, Crea F. Primary coronary microvascular dysfunction: clinical presentation, pathophysiology, and management. Circulation. 2010; 121(21): 2317-2325, doi: 10.1161/CIRCULATIONAHA.109.900191, indexed in Pubmed: 20516386.

3. Ziadi MC, Dekemp RA, Williams KA, et al. Impaired myocardial flow reserve on rubidium-82 positron emission tomography imaging predicts adverse outcomes in patients assessed for myocardial ischemia. J Am Coll Cardiol. 2011; 58(7): 740-748, doi: 10.1016/j.jacc.2011.01.065, indexed in Pubmed: 21816311.

4. De Bruyne B, Pijls NHJ, Kalesan B, et al. FAME 2 Trial Investigators. Fractional flow reserve-guided $\mathrm{PCl}$ versus medical therapy in stable coronary disease. N Engl J Med. 2012; 367(11): 991-1001, doi: 10.1056/NEJMoa1205361, indexed in Pubmed: 22924638.

5. Tonino PA, De Bruyne B, Pijls NH, et al. FAME Study Investigators. Fractional flow reserve versus angiography for guiding percutane- ous coronary intervention. N Engl J Med. 2009; 360(3): 213-224, doi: 10.1056/NEJMoa0807611, indexed in Pubmed: 19144937.

6. Sels JWEM, Tonino PAL, Siebert U, et al. Fractional flow reserve in unstable angina and non-ST-segment elevation myocardial infarction experience from the FAME (Fractional flow reserve versus Angiography for Multivessel Evaluation) study. JACC Cardiovasc Interv. 2011; 4(11): 1183-1189, doi: 10.1016/j.jcin.2011.08.008, indexed in Pubmed: 22115657.

7. Roffi M, Patrono C, Collet JP, et al. Authors. [2015 ESC guidelines for the management of acute coronary syndromes in patients presenting without persistent ST-segment elevation]. [Article in Polish]. Kardiol Pol. 2015;73(12):1207-94. 2015; 73(12): 1207-1294, doi: 10.5603/KP.2015.0243, indexed in Pubmed: 26727671.

8. Tonino PAL, Fearon WF, De Bruyne B, et al. Angiographic versus functional severity of coronary artery stenoses in the FAME study fractional flow reserve versus angiography in multivessel evaluation. J Am Coll Cardiol. 2010; 55(25): 2816-2821, doi: 10.1016/j.jacc.2009.11.096, indexed in Pubmed: 20579537. 